\title{
CAPACITY BUILDING TO IMPROVE HEALTH: A HEALTH PROMOTION PERSPECTIVE
}

\section{Shelley Bowen}

Health Promotion Strategies \& Settings Unit NSW Department of Health

Building capacity to improve health is an important element of effective public health practice. Emerging theory in health promotion sees capacity building as an approach to the development of sustainable skills, organisational structures, resources, and commitment to health improvement in health and other sectors. ${ }^{1,2,5}$ This is achieved by strengthening and improving our capacity to act within programs, and developing the capacity of the health system to respond to emerging issues that affect health. ${ }^{1,2}$

Evidence suggests that building the capacity of the system enables it to prolong and multiply health outcomes from public health programs. ${ }^{1,2,3,5,6,7}$ The Health Promotion Branch, NSW Department of Health, in collaboration with many other partners in NSW, has been working to increase the undertanding of capacity building within the health system. Tools have been developed to assist with strategy development, and for the measurement of a concept that is not new, but which is further developed.

Within their work to map the domains of capacity building and develop indicators to guide practice, Hawe et al. identify three conceptual approaches to capacity building. These are health infrastructure and service development; program maintenance and sustainability; and problem solving capability of organisations and communities (Figure 1). ${ }^{2}$ Their work provides a major step forward for health promotion practitioners by clearly articulating the intent of capacity building efforts.

Capacity building is of particular importance to health promotion because it provides clearer definition, and attempts to measure, what is sometimes described as the 'invisible work' of health promotion. ${ }^{2}$ It is the 'behind the scenes' effort by practitioners that increases the likelihood that effective health promotion programs will be sustained.

In addition, capacity building strengthens evaluation by emphasising the importance of measuring context: it considers sustainability, provides tools to measure the capacity we have against the capacity we need to reach an outcome; and provides a framework for thinking about, not only the capacity within programs, but the capacity of systems-organisations to respond to changing health needs.

The Health Promotion Branch is particularly interested in the application of capacity building strategies and indicators to programs that focus on approaches across settings, priority populations and health issues. Tools that help with the development of strategies and measurement when building capacity are being applied in a number of program areas such as: safe communities, women's health outcomes, tobacco control, Aboriginal health promotion, better practice, health promotion with schools, primary health care transition and youth suicide.,

The focus of the Health Promotion Branch so far has been on:

\section{FIGURE 1}

A WAY OF CONCEPTUALISING CAPACITY BUILDING IN HEALTH PROMOTION

Health Promotion Practice

Within Programs

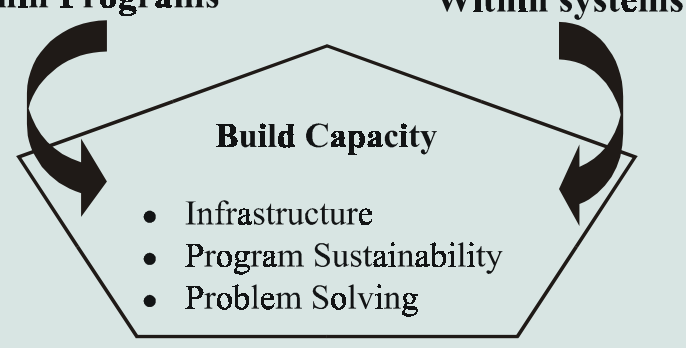

Greater capacity of people, organisations and communities to promote health

Source: Hawe et al. ${ }^{2}$ 
- defining capacity building;

- articulating capacity building strategy (existing and new);

- engaging people in debate about the place and value of capacity building in public health practice;

- investing in research to develop resources to guide the measurement of our previously invisible capacity building effort;

- supporting the transition of capacity building research into practice.

This has been achieved by supporting:

- the publication of indicators to help with capacity building in health promotion that have been developed by the Department of Public Health and Community Medicine at the University of Sydney; ${ }^{2}$

- the development of a strategic framework by NSW Health, Capacity building to improve health $;^{7}$

- the development of the Community Capacity Health Development Index by the University of Queensland; ${ }^{4}$

- the capacity building grant incentive scheme, Putting the latest capacity building indicators research into practice;

- the NSW Health Capacity Building Forum, Achievements, experiences and opportunities for the future-capacity building and public health held at Sydney University in October $1999 ;^{3}$

- a colloquium in March 2000: Capacity Building: Mastering the art of the invisible.

Our challenge now is to encourage the systemic application of these tools by health and other systems; build research into practice; and continue with judicious investment in research, measurement and sustainability of our capacity building effort.

\section{REFERENCES}

1. Hawe P, Noort M, King L, Jordens C. Multiplying Health Gains: the critical role of capacity building within health promotion programs. Sydney: Health Policy Branch, NSW Department of Health, 1997.

2. Hawe P, King L, Noort M, Jordens C, Lloyd B. Indicators to help with capacity building in health promotion. NSW Department of Health and the Australian Centre for Health Promotion, Department of Public Health and Community Medicine, University of Sydney, 2000.

3. Bush R. Achievements, experiences and opportunities for the future-capacity building and public health. Presentation at a NSW Health Capacity Building Forum, Sydney University, Oct 1999. Unpublished.

4. Bush R, Mutch A. District Health Development: Capacity Audit (draft). St Lucia: Centre for Primary Health Care, University of Queensland, 1997.

5. Eade D. Capacity Building: an approach to people-centred development. London: Oxfam, 1997.

6. Kaplan A. Capacity Building: Myth or reality? Community Development Resource Association Annual Report, 1995. www.cdra.org.za.

7. NSW Department of Health. Capacity Building to improve health: a strategic framework, 2000. Sydney: NSW Department of Health, in press.

\section{NSW PUBLIC HEALTH BULLETIN}

The NSW Public Health Bulletin is a publication of the NSW Department of Health. The editor is Dr Lynne Madden, Manager, Public Health Training and Development Unit, NSW Department of Health. Dr Michael Giffin is production manager.

The Bulletin aims to provide its readers with population health data and information to motivate effective public health action.

\section{Submission of articles}

Articles, news and comments should be 1000 words or less in length and include a summary of the key points to be made in the first paragraph. References should be set out in the Vancouver style, described in the New England Journal of Medicine, 1997; 336: 309-315. Send submitted articles on paper and in electronic form, either on disc (Word for Windows is preferred), or by email. The article must be accompanied by a letter signed by all authors. Full instructions for authors are available on request from the editor.

\section{Editorial correspondence}

Please address all correspondence and potential contributions to The Editor, NSW Public Health Bulletin, Locked Mail Bag 961, North Sydney NSW 2059 or to Lmadd@doh.health.nsw.gov.au. Tel (02) 9391 9956, Fax (02) 93919232.

\section{Distribution}

Please contact your local Public Health Unit or telephone (02) 93919942 to obtain copies of the NSW Public Health Bulletin or to notify us of a change of address. The Bulletin can be accessed via the Internet from the Department's Web site at: www.health.nsw.gov.au/public-health/phb/phb.html.

Back issues can be obtained from the Public Health Training and Development Unit, Locked Mail Bag 961, North Sydney NSW 2059. 